and lifestyle factors typical of young people to produce unintended results.

\section{Driver education renaissance?}

\section{A F Williams, S A Ferguson}

\section{Why we need evidence based highway safety policy}

D espite decades of research indicating driver education does not reduce crash involvement among beginning drivers, it still has tremendous popular appeal as a means to improve driver safety. Formal driver education programs enjoy widespread public acceptance around the world as the preferred way to prepare beginners for licensure. For example, a survey in the United States found that $86 \%$ considered driver education courses "very important" in training new drivers to drive safely. Only $2 \%$ thought it was not important. ${ }^{1}$ When the young driver problem is addressed in public forums, there inevitably is an appeal for more or better driver education.

\section{EVALUATIONS OF DRIVER EDUCATION}

Several comprehensive international reviews of the best scientific evaluations of driver education programs for young beginners all come to the same conclusion: There is no difference in the crash records of driver education graduates compared with equivalent groups of beginners who learned to drive without formal education. ${ }^{2-6}$ The most recent review of driver education studies states, "There is little evidence that pre-license training per se reduces crash rates among novice drivers in the short or longer term". ${ }^{2}$

There is little evidence that courses teaching advanced driving maneuvers such as skid control improve driver safety, and they can produce adverse outcomes. These courses have become quite popular in the United States as a way to supplement basic driver education. The courses generally are taught by police or in advanced driving schools using test track facilities. In two studies conducted in the United States and Norway, young males who received such training were found to have higher crash rates than comparable drivers who did not take these courses. ${ }^{78} \mathrm{~A}$ Finnish study reported that both young males and females experienced slightly higher rates of slippery surface crashes after receiving skid training. ${ }^{9}$ A subsequent reanalysis of these data by the same authors reported no effects of the training on young driver crash rates. ${ }^{10}$
Over a four year period, these authors reported a decline in slippery road crashes for young males and young females, noting that the results are "problematic" because of changes in economic conditions and other uncontrolled factors. ${ }^{11}$

\section{WHY DRIVER EDUCATION DOES NOT PRODUCE SAFER DRIVERS}

There is little reason to think driver education should produce drivers less likely to crash. The courses generally are of short duration (for example, 30 hours in-class and six hours in-vehicle); in the available time, it is possible to teach only basic driving skills. There is less opportunity to teach safe driving techniques, and any safety messages that are conveyed can be overwhelmed by ongoing parental, peer, personal, and other social influences that shape driving styles and crash involvement. Such influences largely are beyond the reach of driver education instructors. For the same reasons, many short term high school health education programs aimed at influencing smoking, alcohol, and other drug use have failed, ${ }^{12-16}$ although programs that are comprehensive and longer term, targeting the entire community, have had some success. ${ }^{17-20}$ The audience for driver education courses also may be relatively unmotivated by safety concerns. In surveys, most teenagers say they want to get licensed as soon as possible, and the goal of many driver education students is likely to center on learning enough skills to pass the driving test. ${ }^{21}$ Developmental and lifestyle features typical of young adolescents (risk taking, feelings of invulnerability, immature decision making) also make it difficult to influence the way they drive through safety messages.

It is not entirely clear why the advanced driving/skid control courses increase rather than reduce the crash risk of young males. It seems likely that the courses inspire overconfidence and/ or young people may create extra opportunities to try out these advanced maneuvers, with peer influences playing a part. In any case, this is an example of how skills learned through driver education can interact with developmental

\section{DRIVER EDUCATION AND SKILLS} ACQUISITION

What, then, is pre-license driver educaPat Waller discussed the unrealistic expectations of a high school driver education teacher, compared with the way teachers of other subjects are judged. She asked the question, "Should the driver education teacher be responsible only for whether the student can drive adequately or whether he actually does drive in this manner?" and went on to note the many outside factors that influence subsequent driving performance. ${ }^{22}$

It seems apparent that driver education should be considered as one method for teaching young beginners how to drive adequately, that is, it is a way to learn basic driving skills. Is it the best method? Driver education courses vary, so there is no blanket answer. However, one would expect professional instruction to be superior to lay instruction for teaching skills, and there is some evidence that good programs accomplish this. For example, the Safe Performance Curriculum group in the landmark DeKalb County study received what was considered at the time to be state of the art driver education, and this group scored higher on the Southern California on-road performance test than those in a control group or minimum training group. ${ }^{23}$

\section{DRIVER EDUCATION AND EARLY LICENSURE}

It would be more defensible if driver education were promoted as the best way to learn driving skills rather than as a way to produce safer drivers. However, driver education is not benign. When available at early ages, it is associated with earlier licensure, which leads to additional crashes and injuries. This finding has been reported in several studies in the United States. ${ }^{24-28}$ Many states in the United States require driver education as a condition of licensure before age 18 , so this is one way driver education leads to early licensure (although licensure can be delayed if driver education courses are hard to come by). However, independent of driver education requirements, the easy availability of driver education has been found to lead to earlier licensure in both states where it is optional and states where it is required. ${ }^{27}$ The strength of this relationship was demonstrated when some Connecticut high schools dropped driver education, which led to a $75 \%$ decline in licensure among 16-17 tion able to contribute? In a 1977 article, 
year olds and a substantial decline in crashes. ${ }^{28}$

The relationship between driver education and early licensure also has been reported in studies in Australia, Canada, England, and New Zealand. ${ }^{29-32}$ Earlier licensure enhances mobility, which has important benefits for teenagers, but at the expense of safety.

\section{SUMMARY OF DRIVER EDUCATION EFFECTS}

Here is how the most recent review of the international driver education literature summarizes the situation: "The research literature suggests that, beyond imparting basic car control and road law knowledge skills, pre-license driver training/education contributes little to post-license reductions in casualty crashes or traffic violations among novice drivers. In addition, mandatory pre-license training or even formal prelicense training/education, such as high school driver education programs in the USA, may contribute to increased exposure-to-risk for young drivers, particularly females, by encouraging early solo licensing. There is also considerable evidence that driver training that attempts to impart advanced skills such as skid control to learner drivers may contribute to increased crash risk, particularly among young males. This pattern of results has been confirmed and replicated across numerous studies conducted in Australia, New Zealand, North America, Europe and Scandinavia during the last 30 years". ${ }^{2}$

\section{TIME DISCOUNTS}

Some licensing systems include provisions that implicitly assume driver education graduates are safer drivers. The results are detrimental. For example, some jurisdictions in Canada, the United States, and New Zealand allow beginners with driver education to spend less time in the learner stage of graduated licensing systems. Two states in the United States allow earlier graduation from the late night driving restriction for initial license holders. These time discounts are contrary to graduated licensing principles, which are based on time in the system, and have compromised the overall positive effects of graduated systems. In Nova Scotia, the learner phase can be reduced from six to three months with driver education. Novices who took advantage of this time discount had a crash rate when first licensed that was $27 \%$ higher than newly licensed drivers without driver education. ${ }^{33}$ In Ontario, where the learner period can be reduced from 12 to eight months, novices with driver education had a crash rate when first licensed that was $44 \%$ higher than those who did not take driver education. ${ }^{34}$ The reasons for these differences are not clear but may be related to amounts of exposure. These are not direct tests of the effects of driver education because young drivers self selected whether they would take the course. However, the findings provide a strong argument against special privileges for driver education graduates.

\section{ENDURING APPEAL OF DRIVER EDUCATION}

Despite the scientific evidence that driver education has neutral or negative effects, it has enduring appeal and continues to be sold and promoted on the basis that it enhances safety. Several recent examples illustrate this appeal. In 2000, the British government launched its road safety plan, which included a large component of driver education. After reviewing the research literature, the Cochrane Review Group unsuccessfully protested this development because of concern that "the government's road safety strategy included an intervention that may increase teenage road traffic crashes" ${ }^{35}$

In 2003 Ford Motor Company, in concert with the National Highway Traffic Safety Administration and with the involvement of many major safety organizations in the United States, launched "Real World Driver: Driving Skills for Life", which involves the distribution of educational materials to every public high school (more than 20 000) across the United States. The accompanying press release stated that "most of the crashes and resulting injuries and deaths could be prevented if teenagers better understood the necessary skills for safely driving vehicles". ${ }^{36}$ Decades of research suggest this statement false.

In October 2003, the National Transportation Safety Board convened a two day public forum to "explore the strengths and weaknesses of driver education programs and what can be done to improve them" ${ }^{\prime 37}$

Another example involves BMW. In June 2003, this company introduced a free, nationwide student driving program. The half day course featured instruction in skid control and emergency recovery-that is, instruction that has been shown by research to increase the crash problem. ${ }^{38}$

Driver education is constantly reinventing itself, and several new programs have been developed recently in the United States, Europe, Australia, and New Zealand. ${ }^{39}$ These programs are thoughtfully and carefully planned, but they have not been evaluated. Given the formidable barriers to making young beginners safer drivers through educa- tion and training and the disappointing results of prior evaluations of programs initially thought to be excellent, it is essential to scientifically evaluate new programs before fully launching them.

\section{FUTURE DIRECTIONS FOR DRIVER EDUCATION}

\section{Removing or blunting harmful} effects

One goal should be to remove or blunt any harmful effects of driver education. There are several ways to do this.

1. Having driver education available in high schools is a convenience for many parents, and most educators probably would agree that the public high school system has a part to play in teaching various vocational skills. However, it must be recognized that public funding or other ways of encouraging high school driver education worsen the crash problem for teenagers and eliminating driver education in schools will produce safety benefits by reducing early licensure. Debates about driver education in high schools should take these factors into account. There is no official tally of schools in the United States currently offering driver education, although there has been a trend to drop it, primarily for economic reasons.

2. In the United States, the connection between driver education and early licensing also could be blunted by keeping all young beginners in graduated systems until age 18, with significant driving restrictions. In many current systems, early entry, facilitated by driver education, can lead to early graduation.

3. Special privileges for driver education graduates (time discounts) should be eliminated. New Zealand's original graduated licensing system had discounts in both the learner phase (three months instead of six) and the intermediate phase (eight months instead of 12). The learner phase discount subsequently was eliminated.

4. Although courses that teach crash avoidance skills on test tracks are intuitively appealing, particularly because many driver education courses involve minimal on-road training, greater publicity needs to be given to the findings from research that these courses do not improve safety and can increase crash risk.

\section{New developments in driver education}

Driving experience, not training, is key to becoming a safer driver. There is a 
trend around the world to maximize the amount of experience gained by young beginners before licensure. This is accomplished in North America and Australia through longer mandatory permit periods in licensing systems. It is accomplished in some northern European countries by lowering the permit age. For example, in Sweden the minimum learner's permit age was reduced from 17 years, six months to 16 years in 1997 (the minimum licensing age remained 18). It is well established that driving during the supervised learner period has low crash risk, ${ }^{40}$ and to the extent the learner period is extended this means beginners will not progress to the next licensing stage until they are older and perhaps more mature. Research in Sweden indicates that learners who took advantage of the early permit (and had an average of 118 hours of supervised experience) had 35\% fewer crashes once licensed than those who obtained their permits at age 17 years, six months ( 44 hours of supervised experience). ${ }^{41}$

Much of the supervision of driving in the learner stage will be done by lay instructors, primarily parents, especially when the goals (for example, minimum numbers of hours spent behind the wheel) are set high. For example, parents in many states in the United States have to certify that at least 50 hours of supervised driving has been provided. Road safety organizations in Australia encourage at least 120 hours before solo driving. There is opportunity here for professional driver educators to coordinate with lay instructors to maximize the quantity and quality of driving experience gained. Many of the more recent driver education programs, including Ford's, do this to some extent. In most cases, materials are provided to parents that encourage them to get involved in the learning process, advise them on how to provide supervised driving practice, tell them the importance of following the rules and restrictions of graduated licensing systems, or just give general tips about driving safety for their teenagers.

Other models are possible that provide structured interaction between educators and parents. For example, in Australia the Royal Automobile Club of Victoria provides for such interaction throughout the learning stage, starting with an initial 45-60 minute driving lesson where a parent is invited to join the learner and instructor ( $\mathrm{R}$ Christie, personal communication, 2003). The intention is to encourage parents to ask questions and request advice on how to manage supervised driving instruction, motivate the provision of supervised driving experience, and introduce parents to support and guidance materials on providing supervised on-road experience.

It is not really known what is optimum in terms of amount and type of driving in the learner stage, but presumably the target is the accumulation of miles in a variety of progressively more demanding driving situations. This coordinated approach provides an opportunity to combine professional instruction in driving skills with maximum supervised practice, facilitated by parents guided by professional instructors.

Obviously such an approach would need to be evaluated in rigorous fashion to see if it is better than alternatives. It depends on both the willingness of driver educators to play this role and substantial parent involvement. Results of recent research indicate that increasing parental involvement in the learning-to-drive stage may not be easy. ${ }^{42}$

\section{CONCLUSION}

In the case of pre-license driver education, there is a major discrepancy between public beliefs and scientific knowledge. There is wide public support for programs that, in fact, do not produce safer drivers and can have unintended negative consequences. Of considerable concern is that scarce resources continue to be spent in the name of safety on programs that have no benefit or may even make things worse. In such a case, the wisest course would be to blunt the harmful effects of driver education and redirect it in ways that take advantage of what it can do (that is, teach basic driving skills). Many new approaches are being tried or are under development, but they should not be widely applied unless rigorous assessments indicate they are effective in reducing crash risk.

\section{ACKNOWLEDGEMENTS}

This work was supported by the Insurance Institute for Highway Safety.

Injury Prevention 2004;10:4-7.

doi: 10.1136/ip.2003.004358

\section{Authors' affiliations}

A F Williams, S A Ferguson, Insurance Institute for Highway Safety, Arlington, Virginia, USA

Correspondence to: Allan F Williams, Insurance Institute for Highway Safety, 1005 North Glebe Road, Arlington, VA 22201, USA; research@iihs.org

\section{REFERENCES}

1 National Highway Traffic Safety Administration. 1995 Customer satisfaction survey. Washington, DC: US Department of Transportation, 1996.
2 Christie R. The effectiveness of driver training as a road safety measure: a review of the literature. Victoria, Australia: Royal Automobile Club of Victoria Ltd, 2001.

3 Mayhew DR, Simpson HM, Williams AF, et al. Effectiveness and role of driver education and training in a graduated licensing system. J Public Health Policy 1998;19:51-67.

4 Vernick JS, Li G, Ogaitis S, et al. Effects of high school driver education on motor vehicle crashes, violations, and licensure. Am J Prev Med 1999:16:40-6.

5 Woolley J. In-car driver training at high schools: a literature review. Walkervillle, South Australia: Transport SA, Safety Strategy, 2000.

6 Roberts I, Kwan I, Cochrane Injuries Group Driver Education Reviewers. School based driver education for the prevention of traffic crashes (Cochrane review). The Cochrane Library, Issue 1. Oxford, UK: Update Software Ltd, 2002.

7 Jones B. The effectiveness of skid-car training for teenage novice drivers in Oregon. Salem, OR: Drive and Motor Vehicle Services, 1993.

8 Glad A. Phase 2 driver education, effect on accident risk. Oslo, Norway: Transport Institute, 1988

9 Katila A, Keskinen E, Laapotti S, et al. Changes in slippery road accidents as an effect of renewed driver training in Finland. Turku, Finland: University of Turku, 1995.

10 Katila A, Keskinen E, Hatakka M, et al. Does increased confidence among novice drivers imply a decrease in safety? The effects of skid training on slippery road accidents. Accid Anal Prev (in press).

11 Katila A, Peräaho M, Keskinen E, et al. Long-term effects of the Finnish driver training renewal of 1990. In: Bartl G, ed. DAN report. Results of EUproject: description and analysis and post licensing measures for novice drivers. Vienna, Austria: Austrian Road Safety Board, 2000:71-82.

12 Dielman TE, Shope JT, Leech SL, et al. Differential effectiveness of an elementary school-based alcohol misuse prevention program. J School Health 1989;59:255-63.

13 Ellickson PL, Bell RM, McGuigan K. Preventing adolescent drug use: long-term results of a junior high program. Am J Public Health 1993;83:856-61.

14 Hansen WB, Malotte CK, Fielding JE. Evaluation of tobacco and alcohol abuse prevention curriculum for adolescents. Health Educ $Q$ 1988;15:93-114.

15 Baer JS, MacLean MG, Marlatt GA. Linking etiology and treatment for adolescent substance abuse: towards a better match. In: Jessor R, ed. New perspectives on adolescent risk behavior. Cambridge, UK: Cambridge University Press 1998

16 Ellickson PL, Bell RM. Drug prevention in junior high: a multi-site longitudinal test. Science 1990;247: 1299-305.

17 Shope JT. Preventing risky lifestyle and problem behaviour among adolescents. In: Simpson $\mathrm{H}$, ed. New to the road: reducing the risks for young motorists Proceedings of the First Annual International Symposium of the Youth Enhancement Service. Los Angeles, CA: University of California, 1996:127-38.

18 Pentz MA, Dwyer JH, MacKinnon DP, et al. A multicommunity trial for primary prevention of adolescent drug abuse: effects on drug use prevalence. JAMA 1989;261:3259-66.

19 Perry CL, Williams CL, Veblen-Mortenson S, et al. Project Northland: outcomes of a communitywide alcohol use prevention program during early adolescence. Am J Public Health 1966;86:956-65

20 Centre for Substance Abuse Prevention Promising and proven substance abuse prevention programs. Publication (SMA) 013506. Rockville, MD: US Department of Health and Human Services, 2001.

21 Preusser DF. Delaying teenage licensure. Alcohol Drugs and Driving 1988;4:283-95.

22 Waller PF. Driver education: where does it belong? Journal of Traffic Safety Education 1977;25:7-9.

23 Stock JR, Weaver JK, Ray HW, et al. Evaluation of safe performance secondary school driver 
education curriculum demonstration project. Report No DOT HS-806-568. Washington, DC: US Department of Transportation, 1983.

24 Robertson LS, Zador PL. Driver education and fatal crash involvement of teenaged drivers. Am J Public Health 1978;68:959-65.

25 Seaver WB, Nichols JL, Carlson WL. Driver education and licensing of 16-17-year-olds. J Saf Res 1979;11:50-61

26 Levy DT. Youth and traffic safety: the effects of driving age, experience, and education. Accid Anal Prev 1990;22:327-34.

27 Lund AK, Preusser DF, Williams AF. Licensing decisions of teenagers. Alcohol Drugs and Driving 1987;3:93-105.

28 Robertson LS. Crash involvement of teenaged drivers when driver education is eliminated from high school. Am J Public Health 1980;70:599-603.

29 Shaoul J. The use of accidents and traffic offenses as criteria for evaluating courses in driver education. Salford, UK: University of Salford, 1975.

30 Potvin L. The evaluation of a compulsory driver training policy: Quebec, 1980-1984.
Proceedings of the New to the Road Symposium: Prevention Measures for Young or New Drivers. Halifax, Nova Scotia, Canada, 1991.

31 Langford J. Evaluation of Tasmania's pre-driver education program. Hobart: Road Safety Branch, Department of Transport, Tasmania, 1997.

32 Wynne-Jones JD, Hurst P. The AA driver training evaluation. Traffic Research Report No 33. Wellington, New Zealand: Ministry of Transport, Road Transport Division, 1985.

33 Mayhew DR, Simpson HM, Desmond K, et al Specific and long-tem effects of Nova Scotia's graduated licensing program. Traffic Inj Prev 2003:4:91-7.

34 Boase P. Tasca L. Graduated licensing system evaluation. Interim report for Ontario Ministry of Transportation, Safety Policy Branch, Toronto, Ontario, 1998

35 Cochrane Injuries Group Driver Education Reviewers. Evidence based road safety: the driving standards agency's schools programme. Lancet 2001;358:230-2.

36 Governors Highway Safety Association. Ford launches campaign to help teens hone their driving skills. Press release. Dearborn, Ml: Governors Highway Safety Association, 8 May, 2003.

37 National Transportation Safety Board. Public forum on driver education and training. Washington DC, 2003. Available at: http://www.ntsb.gov/ events/symp_driver_ed/symp_driver_ed.htm.

38 BMW. BMW puts teens behind the wheel in an effort to create safer drivers. Woodcliff Lake, NJ: BMW, 2003. Available at: http:// www.bmwusa.com.

39 Mayhew DR, Simpson HM. The safety value of driver education and training. Inj Prev 2002;8(suppl II):ii3-ii8

40 Mayhew DR, Simpson HM, Pak A. Changes in collision rates among novice drivers during the first months of licensure. Accid Anal Prev 2003;35:683-91.

41 Gregersen N, Berg H, Engström I, et al. Sixteen years age limit for learner drivers in Sweden-an evaluation of safety effects. Accid Anal Prev 2000;32:25-35

42 Simons-Morton BG, Hartos J. How well do parents manage young driver crash risks? J Saf Res 2003;34:91-7. 